\title{
REVIEW
}

LUIGI RIGANTE, MD

Department of Neurosurgery,

Neurological Institute, Cleveland Clinic,

Abu Dhabi, UAE; Clinical Associate

Professor of Surgery, Cleveland Clinic

Lerner College of Medicine of Case West-

ern Reserve University, Cleveland, $\mathrm{OH}$
HAMID BORGHEI-RAZAVI, MD

Section of Skull Base Surgery, Rose Ella

Burkhardt Brain Tumor \& Neuro-Oncology Center,

Cleveland Clinic, Cleveland, $\mathrm{OH}$; Pauline Braathen

Neurological Center, Department of Neurosur-

gery, Cleveland Clinic Florida, Weston, FL
PABLO F. RECINOS, MD, FAANS

Section Head, Skull Base Surgery; Co-Director,

Minimally Invasive Cranial Base and Pituitary

Surgery Program; Rose Ella Burkhardt Brain

Tumor \& Neuro-Oncology Center; Cleveland Clinic,

Cleveland, $\mathrm{OH}$; Assistant Professor of Neurological

Surgery, Cleveland Clinic Lerner College of Medicine

of Case Western Reserve University, Cleveland, $\mathrm{OH}$
FLORIAN ROSER, MD, PhD

Chief of Neurosurgery, Neurological

Institute, Cleveland Clinic, Abu Dhabi, UAE; Clinical Professor of Surgery, Cleveland

Clinic Lerner College of Medicine of Case

Western Reserve University, Cleveland, $\mathrm{OH}$

\section{An overview of endoscopy in neurologic surgery}

\section{ABSTRACT}

Endoscopy allows neurosurgeons to reach regions in the brain and spine through minimally invasive approaches. Such areas were previously accessible only by extensive and invasive approaches that limited the ability to see the areas of interest. Physicians are increasingly caring for patients who have undergone these procedures (eg, for pituitary tumors, hydrocephalus, and other intracranial, peripheral nerve, and spinal problems). This article familiarizes nonneurosurgeons with these techniques.

\section{KEY POINTS}

An increasing number of neurosurgical patients are undergoing endoscopic surgeries of the brain, spine, and peripheral nerves. Familiarization with these techniques provides medical specialists with important knowledge regarding appropriate patient care.

The combination of classic microscopic and endoscopic procedures improves surgical outcomes by increasing surgical maneuverability and reducing manipulation of eloquent structures.

Further innovations in optical physics, electronics, and robotics will dramatically improve the potential of endoscopic neurosurgery in the next decades.
$\mathrm{O}$ VER THE LAST 3 DECADES, the endoscope has become a highly valued visualization tool in neurosurgery, applicable to a broad range of neurosurgical procedures. Following the pace of technological innovations, the quality of the instrumentation has greatly improved along with the status of endoscopy in the neurosurgical field. The use of the endoscope in interdisciplinary extended transnasal approaches revolutionized skull-base surgery. ${ }^{1}$ Transcranial neurosurgery took advantage of the endoscope for inspection, endoscope-assisted, and endoscope-controlled procedures, although the main visualization tool during these interventions remains the operating microscope.

At present, endoscopy has applications in a variety of neurosurgical procedures including transnasal approaches for pituitary and other skull-base tumors, third ventriculostomy, and resection of intraventricular tumors. The range of application is expanding to include extracranial procedures such as peripheral nerve and spine surgery.

\section{CURRENT CONCEPTS}

Hopf and Perneczky ${ }^{2}$ defined the terminology regarding endoscopic procedures and divided them into 3 categories:

Pure endoscopic neurosurgery, ie, procedures performed through working channels under complete endoscopic visualization and with endoscopic instrumentation (Figure 1). ${ }^{3}$

Endoscope-controlled microsurgery, ie, operations performed with standard microsurgical instruments under endoscopic visualization-the microscope is not used (Figure 2).

Endoscope-assisted neurosurgery, ie, the use of both microscope and endoscope during 
The endoscope has become a highly valued tool in neurosurgery

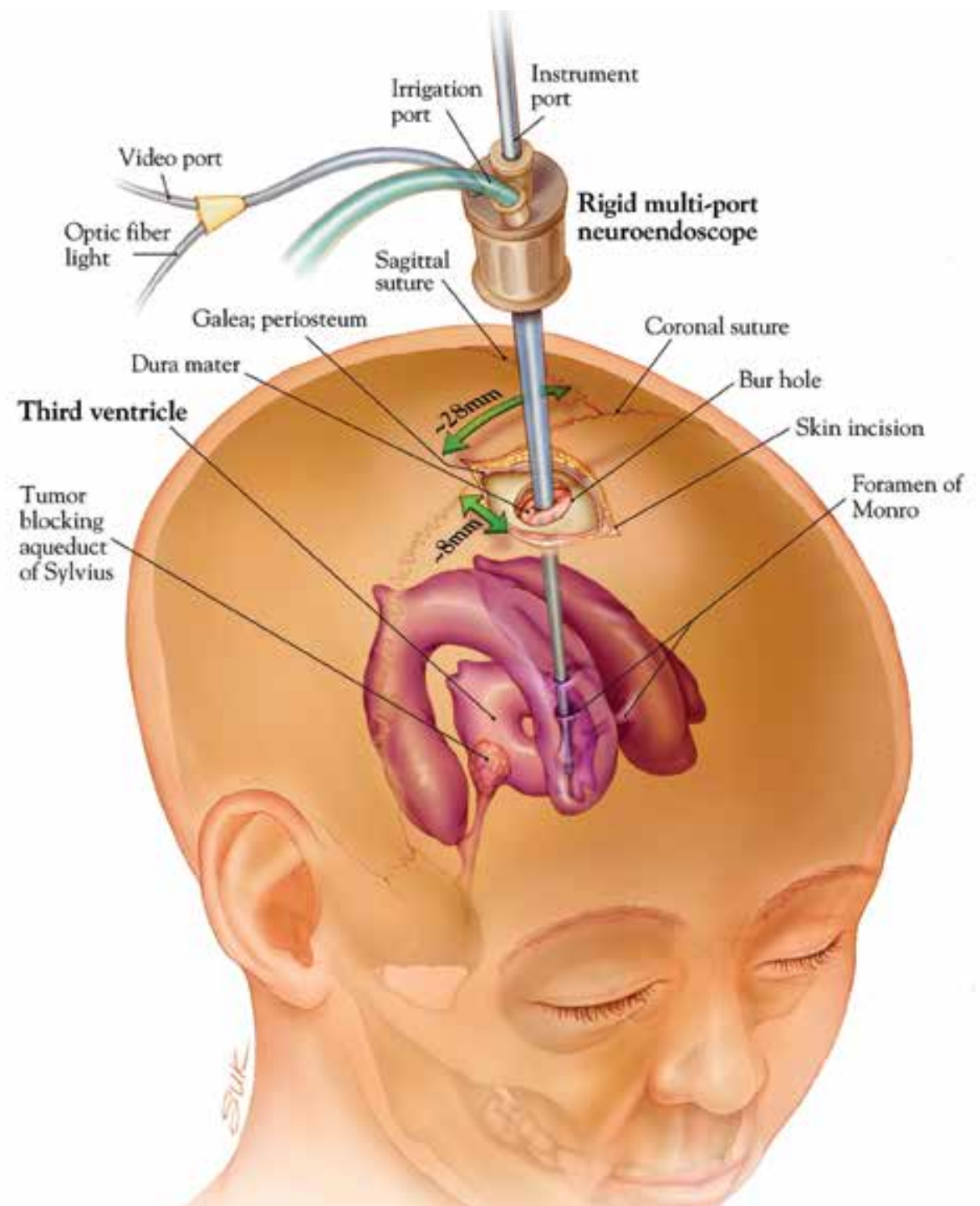

Figure 1. A purely endoscopic neurosurgical procedure. Using this technique, both the optics and instruments are passed through a rigid, multiport chamber. This technique is ideal when performing surgery within the ventricular system using only a standard bur hole craniotomy.

From Li KW, Nelson C, Suk I, Jallo GI. Neuroendoscopy: past, present, and future. Neurosurg Focus 2005; 19(6):E1. Figure used with permission.

the same intervention. In endoscopic inspection the endoscope is solely used as an adjunctive tool for visualization and not for surgical manipulations.

\section{Enhanced area and surgical dissection}

Technical innovations are probably the major reason for the growing role of endoscopy in neurosurgery over the last 3 decades. ${ }^{4}$ Highdefinition imaging, neuronavigation, new instruments, an interdisciplinary approach mostly with ear, nose, and throat (ENT) surgeons, and detailed anatomic studies led to the breakthrough of endoscopic endonasal extended approaches in skull-base surgery. ${ }^{5}$

These endoscopic techniques allow the neurosurgeon to optimize tumor resection, increasing the area of surgical dissection without increasing the size of the surgical approach, 


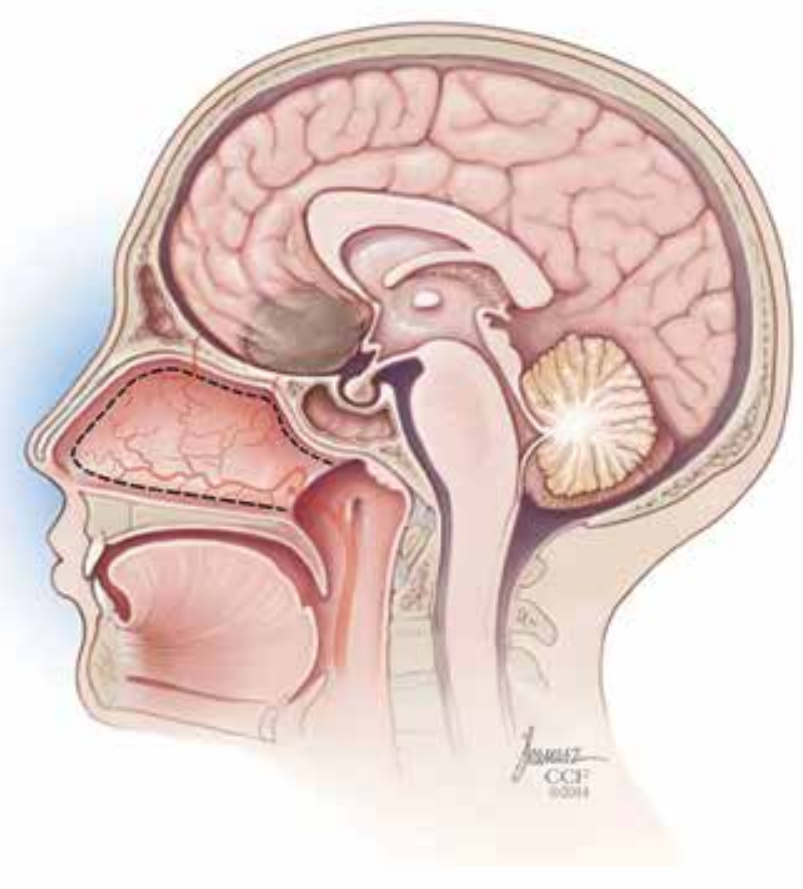

A
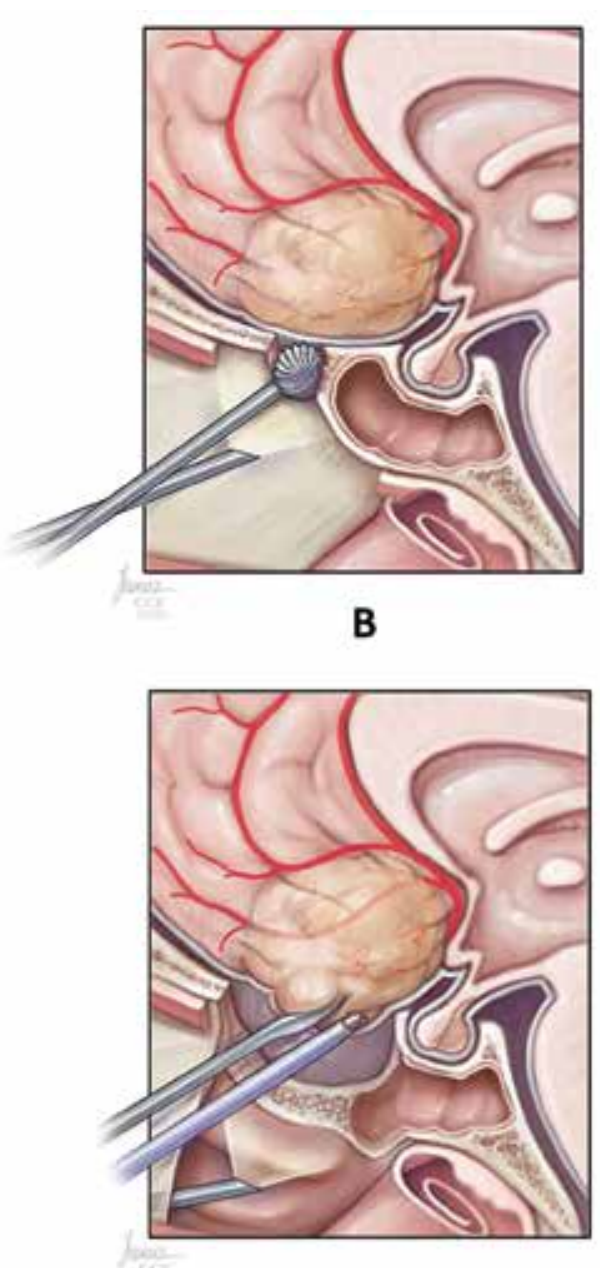

C

Figure 2. A: An anterior skull base meningioma of the planum sphenoidale to be resected with endoscope-controlled microsurgery. B: Unlike purely endoscopic surgery, in this case the endoscope is separate from the surgical instruments and functions as a light source, providing illumination near the region of interest. The base of the skull is first removed utilizing a small, elongated drill. C: The tumor is resected using microsurgical instruments with length and curvature specifically designed for the endonasal corridor.

thereby limiting perioperative morbidity due to surgical manipulation of eloquent brain structures. Endoscopy offers direct illumination of the operative field, magnification, and the ability to look around corners with angled optics.

However, while angled endoscopic optics provide various visual perspectives, the surgical issue is not only to see but also to work on and around remote structures. Microsurgical endoscope-assisted manipulations require optimal working angles that are guaranteed only by a sufficiently large craniotomy. As an example, a dissection study by Chaynes et $\mathrm{al}^{6}$ highlights that a craniotomy that is too narrow often hinders a sufficient exploration of the entire cerebellopontine angle. Most neurosurgeons are familiar with the operating microscope. The microscopic field of inspection is 3-dimensional (3D) and of high quality. However, the light stream is straight and thus limited in the narrow and angled corridor of the cerebellopontine angle or in the perimesencephalic cisterns. In these situations, the angled optic of the endoscope offers the advantage of being able to look around the corner with the appropriate amount of direct illumination. ${ }^{\text {? }}$ 


\section{Peripheral nerve surgery}

Minimally invasive endoscopic approaches are also being used in peripheral nerve surgery, especially carpal tunnel decompression. The first carpal tunnel release treated endoscopically was performed by Okutsu et al in the late 1980s. ${ }^{8}$ Since that time, endoscopic carpal tunnel decompression has become very common and is the preferred method for many surgeons, using either single-portal or dual-portal techniques. Although the superiority of endoscopic over conventional minimally invasive microsurgical peripheral nerve surgeries has not been proven, large series of endoscopic carpal tunnel decompressions have reported low complication rates and excellent success rates with high patient satisfaction scores. ${ }^{8,9}$

\section{Visualization of the spinal canal}

Expanding the use of the endoscope to spine surgery, endoscopic explorations of the interlaminar spaces after having completed open surgical laminectomies have been reported since the early $1980 \mathrm{~s},{ }^{10}$ while endoscope-assisted interlaminar procedures started in the late 1990s. ${ }^{11-13}$ The development of fully endoscop-

Minimally invasive endoscopic approaches are being used in peripheral nerve surgery, especially carpal tunnel decompression ic transforaminal or interlaminar approaches for lumbar stenosis or lumbar disk herniation has been ongoing in the last 2 decades. The rationale for direct endoscopic visualization of the spinal canal is to reduce scarring of the epidural space, which might affect the outcome of possible revision surgeries (recurrent disk herniation), and to reduce injury to the paraspinal muscles, which may reduce postoperative incisional pain and length of hospital stay. Major limiting factors for fully endoscopic spine surgeries such as the narrow working channels (which are limited by the osseous perimeter of the neuroforamina, as well as the pelvis and abdominal structures) and the learning curve for the surgeons are, however, still matters of debate and restrict the use of endoscopy to very carefully selected cases. ${ }^{14,15}$

\section{Pediatric craniosynostosis}

Recently, the use of the endoscope has extended to treatment of craniosynostosis in pediatric patients, historically treated with large and occasionally staged craniotomic approaches. A meta-analysis of the literature showed statistically significant reductions in blood loss and rates of perioperative complications, reoperation, and transfusion compared with open approaches. ${ }^{16}$

\section{Technical limitations}

While neurosurgeons increasingly advocate the use of the endoscope in their practice, the development of instruments for endoscopic surgery does not always follow the same pace. There are technical problems with current rigid endoscopes and ergonomic limitations of the endoscope-assisted techniques in transcranial neurosurgery. The endoscope itself occupies space in an already limited surgical corridor like the posterior fossa, the parasellar space, or the intraventricular region. The ideal endoscope is thin and sturdy, does not generate heat, and provides high-resolution images. In addition, a self-irrigating feature could minimize the need to remove and reinsert the endoscope for cleaning. Finally, most intracranial surgery is extremely delicate and requires bimanual dissection. The ideal endoscope should also be easily integrated with a holder that allows the surgeon to easily transition between static and dynamic endoscope movements.

Newer flexible fiberscopes with even smaller diameters are likely to be launched on the market in the near future. When working in a surgical corridor less than $10 \mathrm{~mm}$ wide, this difference could be substantial.

In addition, surgical instruments specifically designed for endoscopic endonasal procedures are needed for microdissection in these regions, which were previously only visible but not reachable endoscopically. These include tools such as malleable suctions and curettes, rotatable back-biting microscissors, and malleable bipolar instruments (Figure 3).

\section{IMPACT OF NEUROENDOSCOPY IN CURRENT CLINICAL PRACTICE}

The introduction of endoscopy in neurosurgery changed many treatment paradigms and had an important impact on morbidity and outcomes. In this section, we discuss the specific indications, contraindications, and expected benefit of endoscopic vs open surgical approaches applied to neurosurgical pathology at the present time. 


\section{Skull-base tumors and CSF leaks}

The use of the endoscope in skull-base surgery was originally applied to purely midline intrasellar tumors without suprasellar or lateral extension beyond the carotid cave. Ideal cases were intrasellar pituitary microadenomas not responding to medical treatment or Rathke cleft cysts.

These pathologies were traditionally addressed via microscopic craniotomic approaches and later through sublabial or transnasal transsphenoidal approaches. Traditional transsphenoidal approaches were highly invasive for the oral mucosa, causing delayed healing, oral dysesthesia, and, in some cases, loss of the superior dental arch (sublabial) or limited visualization and surgical maneuverability (microscopic endonasal).

The endoscope offered better visualization and surgical freedom, thus allowing higher resection rates to be achieved. Resection of purely intrasellar pathology with preservation of the diaphragma sellae as a barrier to the subarachnoid cysterns and third ventricle guaranteed a lower incidence of cerebrospinal fluid (CSF) leaks.

New endoscope optics with varied angles, together with dedicated long surgical instruments with low steric volume, offered a large variety of new endonasal surgical corridors, so-called expanded endonasal approaches on the sagittal and coronal planes, as discussed in detail by Kassam et al. ${ }^{17-19}$ These allowed endoscopic treatment of invasive tumors extending on the coronary plane into the suprasellar region or invading the cavernous sinuses (pituitary macroadenomas, craniopharyngiomas).

Highly specialized centers with expertise in endoscopic skull-base surgery can now also offer pure endoscopic treatment for some selected cases of lesions located far laterally to the cavernous sinus, such as trigeminal schwannomas, or along the sagittal plane like olfactory groove or tuberculum sellae meningiomas and clival lesions (chordomas, chondrosarcomas).

As one might expect, the increase in surgical complexity corresponded to an increase in complication rates. For example, the incidence of CSF leaks varied from $5 \%$ for standard midline transsphenoidal approaches to $11 \%$ for expanded endonasal approaches. ${ }^{20,21}$ The consolidation of the use of the endoscope
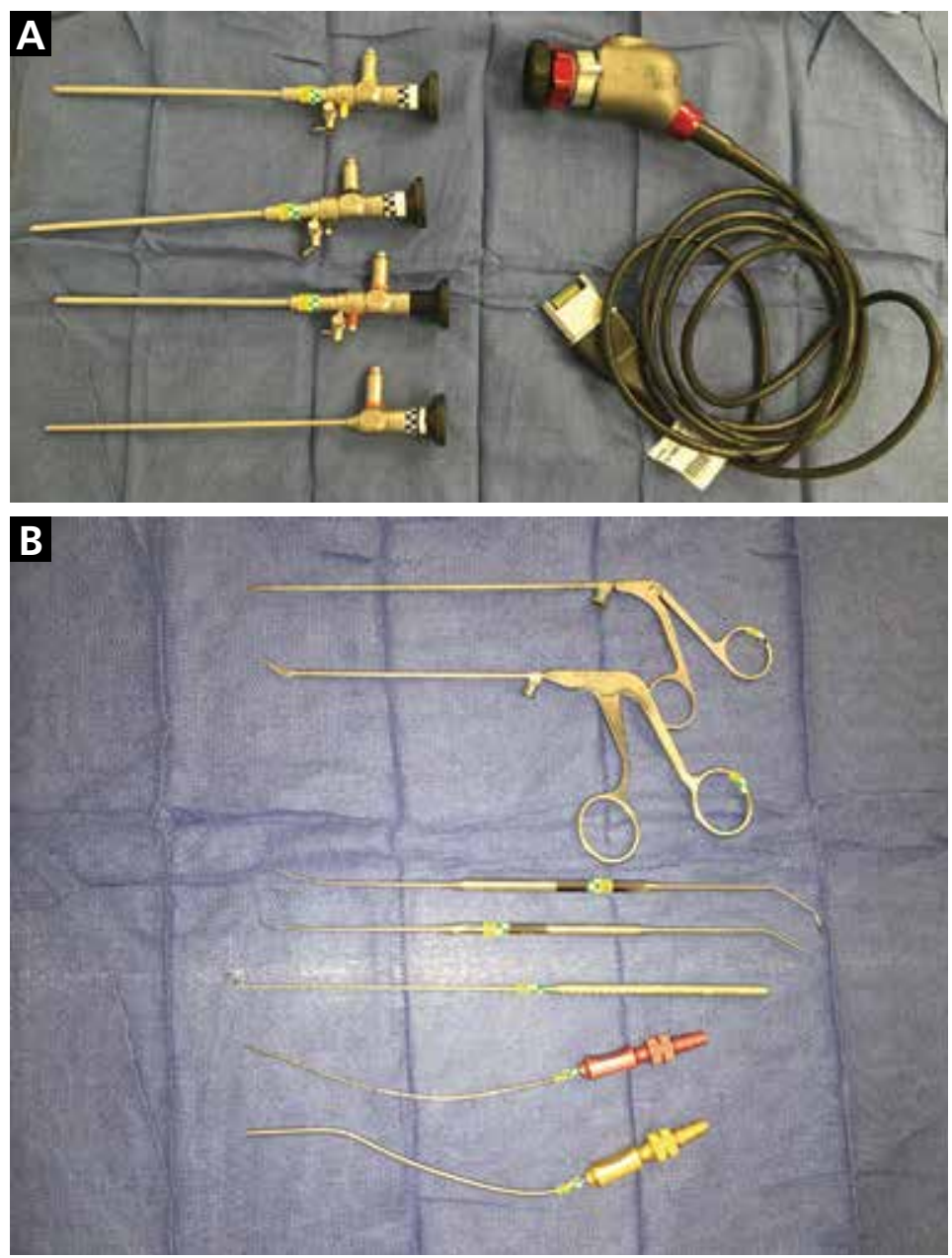

Figure 3. A: Standard $0^{\circ}, 30^{\circ}, 45^{\circ}$, and $70^{\circ}$ angulated endoscopes used in endoscope-controlled microsurgery. The addition of high-definition optics has made endoscopic visualization comparable to microscopy. B: Instruments specifically designed for endoscope-controlled microsurgery, including malleable suctions (lower), angled microcurettes and dissectors, and pistol-grip scissors (upper), have allowed surgical resection of regions previously visible only with the endoscope but not reachable with standard instruments.

and the cooperation with ENT surgeons led to the development of surgical strategies to prevent and reduce the incidence of CSF leaks, such as the use of "rescue flaps," nasoseptal flaps, or temporoparietal fascia flaps. ${ }^{21-23}$

The development of such techniques allowed endoscopic endonasal approaches to be used in treatment of other pathologies, such as spontaneous CSF leaks, treated in the past with large transcranial repairs that carried high morbidity rates due to the surgical fron- 
tal lobe retraction and injury to the olfactory mucosa. ${ }^{24,25}$ Progress in the field of neuroendoscopy therefore led to the creation of specialized endoscopic skull-base surgery centers, including neurosurgery, ENT, ophthalmology, and endocrinology services.

In clinical practice, when evaluating a patient with intracranial skull-base pathology amenable to endoscopic resection, one should consider referring the patient not only to a neurosurgeon, but also to an ENT surgeon for preoperative assessment of the sinonasal cavities. The same concept applies to postsurgical follow-up, which is mostly performed by the ENT physician to assess nasal mucosa healing and nasal hygiene.

\section{Ventricular neuroendoscopy}

The introduction of endoscopic third ventriculostomy created the opportunity to offer a more physiologic treatment in selected patients with obstructive hydrocephalus by creating an internal CSF diversion through the basal cisterns. Two advantages of this procedure are that it does not create dependence on a CSF shunt, and it eliminates the related risks of shunt infection and malfunction. Its draw-

\section{Endoscopic} neurosurgery changed many treatment paradigms

and had an important impact on morbidity and outcomes back is the recurrence rate of hydrocephalus (around $58 \%$ at 2 years of follow-up) due to formation of scarring in the perforated Liliequist membrane, which may require repeat surgery or conversion to CSF shunting. ${ }^{26,27}$

Neuroendoscopic approaches are also used in cases of purely intraventricular pathology such as colloid cyst or choroid plexus papillomas. The concept behind neuroendoscopy is to achieve maximal resection in a minimally invasive way, using the natural cavity of the cerebral ventricles and reducing the need for brain retraction and, in particular, the risk of injury of the fornix (therefore causing memory deficits) of open transventricular approaches and of the corpus callosum necessary in interhemispheric approaches. Large tumor size and inability to tolerate a longer surgical procedure can be relative contraindications to a pure endoscopic approach to these lesions.

\section{Degenerative spine disease}

In recent years there has been a growing interest in the use of endoscopy for selected cases of degenerative lumbar spondylosis (generally, lateral disk herniation above the L5-S1 level or spinal canal stenosis). This approach has been shown to reduce postoperative incisional pain, scarring of the epidural space affecting the outcome of possible revision surgeries (recurrent disc herniation), and length of hospital stay. ${ }^{14,15}$ Information on surgical nuances should be provided when consulting on selected patients with lumbar degenerative disease resistant to conservative treatment.

\section{Carpal tunnel syndrome}

Although endoscopic carpal tunnel release is controversial, its supporters report smaller incision size and lower recurrence rates due to better visualization of the entire carpal ligament compared with open surgery, with high patient satisfaction scores. ${ }^{8,9,28}$

\section{Craniosynostosis}

Increasing data from specialized centers show that early endoscopic suturectomy is an effective treatment option alone or when combined with open surgeries for patients with syndromic and nonsyndromic craniosynostosis. The aesthetic advantage of small incisions (which can also be achieved with some open techniques) is accompanied by significant reductions in blood loss (median $162.4 \mathrm{~mL}$ ), operative time (median 112.38 minutes), length of stay (median 2.56 days), and rates of perioperative complications (odds ratio 0.58), reoperation (odds ratio 0.37 ), and transfusion (odds ratio 0.09) compared with open approaches. ${ }^{16}$

\section{SURGICAL TRAINING}

Today's patients expect high-quality healthcare, and they approach their surgeons with an enormous amount of information collected through unlimited Web-based access or peergroup blogs. In this respect, the pressure on young surgeons to achieve excellent results is high and growing from the very beginning of their careers.

Residency training programs differ in each country, and surgical standards usually focus on open microscopic procedures rather than newly developed endoscopic techniques. Endoscopic pituitary adenoma surgery, the most frequent neuroendoscopic procedure, is still performed mostly by experienced neurosurgeons, not trainees. Moreover, many training institutions 
might not offer pediatric neurosurgery care, limiting exposure to endoscopic third ventriculostomy procedures. The European Union of Medical Specialists, responsible for harmonizing and improving the quality of training of medical specialists in Europe, set low neuroendoscopic surgical requirements for trainees to complete their residency programs (minimum of 0 to optimum of 5 total transcranial or transsphenoidal pituitary adenoma resections as first operator, 10 procedures as assistant, and a minimum of 2 to an optimum of 4 endoscopic third ventriculostomies as first operator). ${ }^{29}$

The need to develop training programs in neuroendoscopy is especially urgent because endoscopic surgery has a steeper learning curve than conventional microneurosurgery. In particular, endoscopy requires a good deal of dexterity and hand-eye coordination, which surgeons consider the main pitfall of neuroendoscopy. For such reasons, many accredited clinical fellowship programs have been developed inside and outside North America that offer intensive training in endoscopic skullbase surgery and pediatric neurosurgery after residency.

Some clinical studies have shown that the complication rate of neuroendoscopy is $15 \%$ to $18 \% .{ }^{27,30}$ In view of this statistic, it is ethically questionable to perform a randomized study to prospectively compare microscopic and endoscopic procedures. Surgeons specialize in one technique or the other, experience their own learning curve, and do not randomly decide which tool to use. Furthermore, every intracranial surgical exploration is unique and somewhat difficult to compare with each other without the risk of bias.

\section{FURTHER DEVELOPMENTS}

Multivariable rigid endoscopes like the EndoCAMeleon (Karl Storz, Tuttlingen, Germany) or the EndActive (Karl Storz, Tuttlingen, Germany) for cerebellopontine angle surgery represent a starting point to overcome some of the aforementioned limitations. ${ }^{31,32}$ They are inserted in the surgical field with a direct $0^{\circ}$ angulation view into the operative site beyond neurovascular structures that need to be preserved and that obstruct the microscopic view. Once the final position is reached, the field of view is directed toward the region of interest without moving the endoscope tip.

The EndoCAMeleon is a rigid rod-lens endoscope, steerable in one plane from $-10^{\circ}$ to $+120^{\circ}$ by a fine optomechanical mechanism. Anatomic laboratory testing found it to be superior in terms of usability and visualization compared with rigid fixed-angle endoscopes. ${ }^{31}$ The first clinical experiences have been promising; however, ergonomics and the limited perspective of a single plane of rotation leave room for improvement.

The EndActive endoscope might overcome such limitations. ${ }^{33}$ This device is a rigid videoendoscope connected to a laptop (video data) and USB port (control and power supply); thus, it weighs less and can be held in one hand like a microsurgical instrument. The endoscopic imaging system allows the operator to simultaneously see a $160^{\circ}$ wide-angle view of the site and an inset of a specific region of interest. The surgeon can hold the device like a microsurgical instrument in one hand and control movements precisely due to its reduced weight and ergonomic shape.

The multiplanar variable-view rigid endoscope has proven to be useful for working on diverse anatomic structures such as intracranial vessels and cranial nerves. The device is effective in narrow working spaces where even small movements can jeopardize the delicate surrounding structures. The multiplanar variable-viewing mechanism in a compact device offers advantages in terms of safety and ergonomics. Improving the usability will probably optimize the applicability of those endoscopic devices in neurosurgery. A major drawback of the current prototype is poor image resolution, which will probably soon be overcome with the ongoing progress in electronic microchip technology.

The addition of laser technology to endoscopic techniques offers a huge potential to neurosurgery but has achieved little acceptance to date. The reasons include concern regarding heat production, uncontrollable and distant penetration, and tissue interaction. Experiences with a 2-micron continuouswave laser (RevoLix Jr, LISA Laser Products, Katlenburg-Lindau, Germany) for neuroendoscopic intraventricular procedures proved this laser to be a valuable and useful tool with safe

\section{Consider} consulting an ENT surgeon and a neurosurgeon in cases of skull-base tumors 
applicability for endoscopic intracranial procedures in patients of all ages. ${ }^{34}$

Parallel to the launch of video screens for other uses with higher image definition, the image quality on the 2D endoscope cameras has been constantly improving over the last years. At the same time, the introduction of modern $3 \mathrm{D}$ endoscopic monitors is promising. However, 3D endoscopes have some disadvantages compared with the $2 \mathrm{D}$ endoscopes. First, the smallest 3D endoscopes are $4 \mathrm{~mm}$ in diameter, compared with $2.7 \mathrm{~mm}$ for 2D endoscopes. Moreover, the field of view with the 3D endoscope is less than half of that with conventional 2D endoscopes. ${ }^{34}$ When working in and around a region with critical neurovascular structures in close proximity, this loss of field of view can result in an increase in iatrogenic injury from the endoscope. In addition, 3D endoscopes require special glasses, generating a potential obstacle to the seamless integration of visual information from the microscope and endoscope. Finally, some surgeons experience vertigo when looking at the 3D picture through the glasses, which limits its universal applicability.

\section{CONCLUSIONS}

Using the endoscope and microscope as complementary and not competing tools al- lows surgeons to benefit from both technologies at the same time..$^{35,36}$ The intraoperative combination of these 2 powerful visualization tools expands the effectiveness of microsurgical procedures and has the potential to further improve surgical results and reduce surgical risks. With endoscope-assisted microsurgery, visualization is often far superior to surgical maneuverability.

Endoscopic neurosurgery will likely be influenced by further innovations in optical physics, electronics, and robotics. Specific implementations in endoscopic systems are likely to pave the way for remarkable progress in minimally invasive surgery, such as robotic surgical technology, further miniaturization of devices, improvements in 3D endoscopy, multiport endoscopy, and new designs for surgical instruments. Future progress in flexible endoscopes and wireless capsule or camera technology may reduce our dependence on rigid rod lens systems. Rigid variable-view endoscopes will bring endoscopes closer to ideal attributes utilizing newer instrumentation that is tailored to specific indications and techniques. ${ }^{37,38} \mathrm{Ex}$ tension of the visual field by the feature of a movable optic lens may allow the neurosurgeon to use tailored keyhole approaches to treat pathologies in smaller surgical corridors with less trauma and greater efficacy.

\section{REFERENCES}

1. Kassam AB, Gardner P, Snyderman C, Mintz A, Carrau R. Expanded endonasal approach: fully endoscopic, completely transnasal approach to the middle third of the clivus, petrous bone, middle cranial fossa, and infratemporal fossa. Neurosurg Focus 2005; 19(1):E6. pmid: 16078820

2. Hopf NJ, Perneczky A. Endoscopic neurosurgery and endoscopeassisted microneurosurgery for the treatment of intracranial cysts. Neurosurgery 1998; 43(6):1330-1336. doi:10.1097/00006123-199812000-00037

3. Li KW, Nelson C, Suk I, Jallo GI. Neuroendoscopy: past, present, and future. Neurosurg Focus 2005; 19(6):E1. doi: 10.3171/foc.2005.19.6.2

4. Prevedello DM, Doglietto F, Jane JA Jr, Jagannathan J, Han J, Laws ER Jr. History of endoscopic skull base surgery: its evolution and current reality. J Neurosurg 2007; 107(1):206-213. doi:10.3171/JNS-07/07/0206

5. Schroeder HW, Nehlsen M. Value of high-definition imaging in neuroendoscopy. Neurosurg Rev 2009; 32(3):303-308. doi:10.1007/s10143-009-0200-x

6. Chaynes P, Deguine O, Moscovici J, Fraysse B, Becue J, Lazorthes Y. Endoscopic anatomy of the cerebellopontine angle: a study in cadaver brains. Neurosurg Focus 1998; 5(3):e8. doi:10.3171/foc.1998.5.6.9

7. Setty P, Volkov AA, D'Andrea KP, Pieper DR. Endoscopic vascular decompression for the treatment of trigeminal neuralgia: clinical outcomes and technical note. World Neurosurg 2014; 81(3-4):603608. doi:10.1016/j.wneu.2013.10.036
8. Okutsu I, Hamanaka I, Yoshida A. Retrospective analysis of five-year and longer clinical and electrophysiological results of the world's first endoscopic management for carpal tunnel syndrome. Hand Surg 2013; 18(3):317-323. doi:10.1142/S0218810413500330

9. Zuo D, Zhou Z, Wang H, et al. Endoscopic versus open carpal tunnel release for idiopathic carpal tunnel syndrome: a meta-analysis of randomized controlled trials. J Orthop Surg Res 2015; 10:12. doi:10.1186/s13018-014-0148-6

10. Forst R, Hausmann B. Nucleoscopy-a new examination technique. Arch Orthop Trauma Surg 1983; 101(3):219-221. pmid:6870510

11. Brayda-Bruno M, Cinnella P. Posterior endoscopic discectomy (and other procedures). Eur Spine J 2000; 9(suppl 1):S24-S29. pmid:10766054

12. Destandau J. A special device for endoscopic surgery of lumbar disc herniation. Neurol Res 1999; 21(1):39-42. pmid:10048052

13. Perez-Cruet MJ, Foley KT, Isaacs RE, et al. Microendoscopic lumbar discectomy: technical note. Neurosurgery 2002; 51 (5 suppl):S129S136. pmid: 12234440

14. Ruetten S, Komp M, Merk H, Godolias G. Full-endoscopic interlaminar and transforaminal lumbar discectomy versus conventional microsurgical technique: a prospective, randomized, controlled study. Spine (Phila Pa 1976) 2008; 33(9):931-939. doi:10.1097/BRS.0b013e31816c8af7

15. Komp M, Hahn P, Merk H, Godolias G, Ruetten S. Bilateral operation of lumbar degenerative central spinal stenosis in full-endoscopic interlaminar technique with unilateral approach: prospective 2-year results of 74 patients. J Spinal Disord Tech 2011; 24(5):281-287. 
doi:10.1097/BSD.0b013e3181f9f55e

16. Goyal A, Lu VM, Yolcu YU, Elminawy M, Daniels DJ. Endoscopic versus open approach in craniosynostosis repair: a systematic review and meta-analysis of perioperative outcomes. Childs Nerv Syst 2018; 34(9):1627-1637. doi:10.1007/s00381-018-3852-4

17. Kassam AB, Gardner P, Snyderman C, Mintz A, Carrau R. Expanded endonasal approach: fully endoscopic, completely transnasal approach to the middle third of the clivus, petrous bone, middle cranial fossa, and infratemporal fossa. Neurosurg Focus 2005; 19(1):E6. pmid: 16078820

18. Kassam A, Snyderman CH, Mintz A, Gardner P, Carrau RL. Expanded endonasal approach: the rostrocaudal axis. Part II. Posterior clinoids to the foramen magnum. Neurosurg Focus 2005; 19(1):E4. pmid: 16078818

19. Kassam A, Snyderman CH, Mintz A, Gardner P, Carrau RL. Expanded endonasal approach: the rostrocaudal axis. Part I. Crista galli to the sella turcica. Neurosurg Focus 2005; 19(1):E3. pmid:16078817

20. Kassam A, Carrau RL, Snyderman CH, Gardner P, Mintz A. Evolution of reconstructive techniques following endoscopic expanded endonasal approaches. Neurosurg Focus 2005; 19(1):E8. pmid:16078822

21. Kassam AB, Thomas A, Carrau RL, et al. Endoscopic reconstruction of the cranial base using a pedicled nasoseptal flap. Neurosurgery 2008; 63(1 suppl 1):ONS44-ONS52. doi:10.1227/01.NEU.0000297074.13423.F5

22. Hadad G, Bassagasteguy L, Carrau RL, et al. A novel reconstructive technique after endoscopic expanded endonasal approaches: vascular pedicle nasoseptal flap. Laryngoscope 2006; 116(10):1882-1886. doi:10.1097/01.mlg.0000234933.37779.e4

23. Fortes FS, Carrau RL, Snyderman CH, et al. Transpterygoid transposition of a temporoparietal fascia flap: a new method for skull base reconstruction after endoscopic expanded endonasal approaches. Laryngoscope 2007; 117(6):970-976. doi:10.1097/MLG.0b013e3180471482

24. Carrau RL, Snyderman CH, Kassam AB. The management of cerebrospinal fluid leaks in patients at risk for high-pressure hydrocephalus. Laryngoscope 2005; 115(2):205-212. doi:10.1097/01.mlg.0000154719.62668.70

25. Zweig JL, Carrau RL, Celin SE, et al. Endoscopic repair of cerebrospinal fluid leaks to the sinonasal tract: predictors of success. Otolaryngol Head Neck Surg 2000; 123(3):195-201. doi:10.1067/mhn.2000.107452

26. Kulkarni AV, Riva-Cambrin J, Holubkov R, et al. Endoscopic third ventriculostomy in children: prospective, multicenter results from the Hydrocephalus Clinical Research Network. J Neurosurg Pediatr 2016; 18(4):423-429. doi:10.3171/2016.4.PEDS163

27. Ersahin Y, Arslan D. Complications of endoscopic third ventriculostomy. Childs Nerv Syst 2008; 24(8):943-948. doi:10.1007/s00381-008-0589-5
28. Martínez-Catasús A, Lobo-Escolar L, García-Bonet J, Corrales-Rodríguez M, Pasarín-Martínez A, Berlanga-de-Mingo D. Comparison between single portal endoscopic, 1-cm open carpal tunnel release. Hand Surg Rehabil 2019. pii:S2468-1229(19)30027-1. doi:10.1016/j.hansur.2019.02.003

29. Steers J, Reulen HJ, Lindsay K; European Union of Medical Specialists; Joint Residency Advisory and Accreditation Committee. UEMS charter on training of medical specialists in the EU-the new neurosurgical training charter. Acta Neurochir Suppl 2004; 90:3-11. pmid: 15553111

30. Mori H, Nishiyama K, Yoshimura J, Tanaka R. Current status of neuroendoscopic surgery in Japan and discussion on the training system. Childs Nerv Syst 2007; 23(6):673-676. doi:10.1007/s00381-007-0329-2

31. Aryan HE, Hoeg HD, Marshall LF, Levy ML. Multidirectional projectional rigid neuro-endoscopy: prototype and initial experience. Minim Invasive Neurosurg 2005; 48(5):293-296. doi:10.1055/s-2005-915602

32. Ebner FH, Marquardt JS, Hirt B, Tatagiba M, Schuhmann MU. Visualization of the anterior cerebral artery complex with a continuously variable-view rigid endoscope: new options in aneurysm surgery. Neurosurgery 2010; 67(2 suppl operative):321-324. doi:10.1227/NEU.0b013e3181f74548

33. Ebner FH, Hirt B, Marquardt JS, Herlan S, Tatagiba M, Schuhmann MU. Actual state of EndActive ventricular endoscopy. Childs Nerv Syst 2012; 28(1):87-91. doi:10.1007/s00381-011-1537-3

34. Ebner FH, Nagel C, Tatagiba M, Schuhmann MU. Efficacy and versatility of the 2-micron continuous wave laser in neuroendoscopic procedures. Acta Neurochir Suppl 2012; 113:143-147. doi:10.1007/978-3-7091-0923-6 29

35. Van Gompel JJ, Tabor MH, Youssef AS, et al. Field of view comparison between two-dimensional and three-dimensional endoscopy. Laryngoscope 2014; 124(2):387-390. doi:10.1002/lary.24222

36. Ebner FH, Roser F, Thaher F, Schittenhelm J, Tatagiba M. Balancing the shortcomings of microscope and endoscope: endoscope-assisted technique in microsurgical removal of recurrent epidermoid cysts in the posterior fossa. Minim Invasive Neurosurg $2010 ; 53(5-6): 218$ 222. doi:10.1055/s-0030-1267973

37. Perneczky A, Fries G. Endoscope-assisted brain surgery: part 1evolution, basic concept, and current technique. Neurosurgery 1998; 42(2):219-224. doi:10.1097/00006123-199802000-00001

38. Ebner FH, Marquardt JS, Hirt B, Feigl GC, Tatagiba M, Schuhmann MU. Broadening horizons of neuroendoscopy with a variableview rigid endoscope: an anatomical study. Eur J Surg Oncol 2010; 36(2):195-200. doi:10.1016/j.ejso.2009.07.185

ADDRESS: Luigi Rigante, MD, Department of Neurosurgery, Neurological Institute, Cleveland Clinic Abu Dhabi, Al Maryah Island, P.O. Box 112412, Abu Dhabi, UAE; rigant/@clevelandclinicabudhabi.ae 